\title{
Prevalence and factors associated with early initiation of breastfeeding among women in Moshi municipal, northern Tanzania
}

Hadija Y. Lyellu ${ }^{1 \dagger}$, Tamara H. Hussein ${ }^{2,3 \dagger}$, Margareta Wandel ${ }^{3}$, Babill Stray-Pedersen ${ }^{4}$, Melina Mgongo ${ }^{2,5^{*}}$ (i) and Sia E. Msuya ${ }^{1,6,7}$

\begin{abstract}
Background: Early initiation of breastfeeding (EIBF) is a predetermining factor for exclusive breastfeeding, and thus a foundation for optimal breastfeeding practices. Rates of EIBF are low globally (42\%) and in Tanzania (51\%), yet few studies have been done on this issue in Tanzania. This study aimed to determine the prevalence and factors associated with early initiation of breastfeeding among women in northern Tanzania.

Methodology: This study extracted information from a cohort of 536 women who were followed from 3rd trimester period October 2013 to December 2015 in Moshi municipal, northern Tanzania. The data for this paper was collected by the use of questionnaires at enrolment, delivery and 7 days after delivery. The analysis is based on data from 413 women for whom complete information was obtained. Log binomial regression analysis was used to determine factors associated with early initiation of breastfeeding.

Results: The prevalence of EIBF was 83\%. Overall, women had high knowledge on colostrum (94\%), knowledge on exclusive breastfeeding (81\%) and time of breastfeeding initiation (71\%), but only 54\% were counseled on breastfeeding during antenatal care. Knowledge on timely initiation of breastfeeding during pregnancy and vaginal delivery were associated with EIBF.

Conclusion: Early initiation of breastfeeding is high (83\%) in Moshi Municipal but still below the universal coverage recommended by WHO and UNICEF. There is missed opportunity by health facilities to counsel and support early initiation of breastfeeding given high antenatal and facility delivery in this setting. There is a need to evaluate health facility bottle necks to optimal support of early initiation of breastfeeding in Tanzania.
\end{abstract}

Keywords: Breastfeeding, Early initiation of breastfeeding, Breastfeeding initiation, Prevalence, Factors, Tanzania

\footnotetext{
* Correspondence: linnabenny@yahoo.com

${ }^{\dagger}$ Hadija Y. Lyellu and Tamara H. Hussein contributed equally to this work.

${ }^{2}$ Better Health for African Mother and Child (BHAMC), P.O. Box 8418, Moshi,

Tanzania

${ }^{5}$ Institute of Clinical Medicine, University of Oslo, Oslo, Norway

Full list of author information is available at the end of the article
}

(c) The Author(s). 2020 Open Access This article is licensed under a Creative Commons Attribution 4.0 International License, which permits use, sharing, adaptation, distribution and reproduction in any medium or format, as long as you give appropriate credit to the original author(s) and the source, provide a link to the Creative Commons licence, and indicate if changes were made. The images or other third party material in this article are included in the article's Creative Commons licence, unless indicated otherwise in a credit line to the material. If material is not included in the article's Creative Commons licence and your intended use is not permitted by statutory regulation or exceeds the permitted use, you will need to obtain permission directly from the copyright holder. To view a copy of this licence, visit http://creativecommons.org/licenses/by/4.0/. The Creative Commons Public Domain Dedication waiver (http://creativecommons.org/publicdomain/zero/1.0/) applies to the data made available in this article, unless otherwise stated in a credit line to the data. 


\section{Introduction}

Early initiation of breastfeeding, defined as initiation of breastfeeding within $1 \mathrm{~h}$ after birth, is considered as one of the key interventions in ending preventable neonatal and child deaths and improving child survival [1-7]. Initiation of breastfeeding within the first hour of birth gives the best possible start in life. It increases the chances that newborns receives the first milk "colostrum", that is rich in antibodies and nutrients, vital in protecting the newborn against infections [4, 6-10]. Immediate skin-to-skin contact which is important in facilitating early initiation of breastfeeding helps in regulation of newborns body temperature, and thus survival $[1,4]$. Maternal advantages of early initiation of breastfeeding include stimulation of oxytocin release that helps uterus to contract hence reducing the risk of postpartum hemorrhage $[11,12]$. It also enhances early bonding between mother and newborn and in establishing exclusive breastfeeding and continued breastfeeding $[4,5]$.

Despite neonatal, infant and maternal benefits of early initiation of breastfeeding, the rates are low. Globally only $42 \%$ of newborns were breastfed within $1 \mathrm{~h}$ of birth in 2017, an increase from 37\% in 2005 [1]. In Asia early initiation of breastfeeding ranged from 32 to $40 \%[1,5$, 13]. In Sub Saharan Africa (SSA) the prevalence of early initiation of breastfeeding vary; $40 \%$ in West and Central Africa, 65\% in Southern Africa, 62\% in Kenya, 66\% in Uganda and $80 \%$ in Rwanda [5, 13]. Tanzania however has a different trend to other East African countries. The prevalence of early initiation of breastfeeding has been fluctuating. In 2004, the rate was 59, 49\% in 2010 and $51 \%$ in 2016 [14]. Thus identifying individual and facility factors that influences early initiation of breastfeeding is important.

Numerous factors have been associated with early initiation of breastfeeding. These include; cultural practices (like giving prelacteal feeding), antenatal care attendance, delivery at the Baby Friendly Hospital Initiative (BFHI) facility, mode of delivery, skilled birth attendant use and number of children [15-21]. Studies in South Asia, Nigeria and Tanzania have shown women who delivered at health facilities had 1.5-2 times higher odds of initiating breastfeeding within $1 \mathrm{~h}$ after birth than those delivered at home $[14,17,18]$.

Globally different interventions have been implemented to protect, promote and support early initiation of breastfeeding. These includes the International Code for Marketing Breast-milk Substitute (1981), (BFHI) in 1991 and the global strategy for infant and young child feeding practices in 2000 [1, 5, 13].

Tanzania have adopted BFHI intervention for about 30 years, but the intervention is sub-optimally implemented. It is recoginsed that health care providers are key to the implementation of BFHI and to provide suportive skills to help mothers to position the baby during breastfeeding. However a study by Mlay (2011) showed that health care providers have inadequate skills to help and support mothers to initiate breastfeeding [22]. This is a missed opportunity since 65 and $91 \%$ of deliveries are occuring at the health facility at national and Kilimanjaro region respectively [14]. Accoding to Demographic and Health Survey (DHS) report, the rates of EIBF have been flactuating with a marked variations between regions ranging between 26 to $80 \%$ [14, 23, 24].

These variations in prevalence of early initiation of breastfeeding call for studies to understand the context regarding dynamics and factors associated with early initiation of breastfeeding at different settings. This study therefore aimed to determine prevalence and factors associated with early initiation of breastfeeding among women in Moshi Municipal, northern Tanzania. The information will contribute to improve EIBF practices which is one of the vital intervention to accelerate the achievement of Sustainable Development Goal (SDG) 3.2 of reducing preventable newborn deaths to 12 per 1000 live births by $2030[5,25]$.

\section{Methods}

\section{Study site and design}

The study was conducted in Moshi municipal council, situated in northern Tanzania. Moshi municipal is one of the seven districts of Kilimanjaro region. According to the Tanzania Census of 2012, Kilimanjaro region had a total population of about 1.64 million people and Moshi municipal council had estimated population of 185,000 and 57,000 women of reproductive age [26]. The economic activities in Moshi municipal council include business, tourism, small scale industries and small farming. By the end of 2017, Moshi municipal had 21 wards, 64 streets and 51 health facilities. The facilities are four hospitals, eight health centers, and rest dispensaries, owned by government, religious organizations and Non Governmental Organization (NGOs). There are 25 health facilities that provide reproductive and child health $(\mathrm{RCH})$ services and delivery services are offered at eight facilities i.e. four hospitals and four government health centers.

The analysis of this study was part of larger cohort study that was conducted between October 2013 and December 2015 in two government primary health centers, i.e. Majengo and Pasua. The two clinics are the largest primary health centres in Moshi municipality; catch a huge population of pregnant women in Moshi urban and offer $\mathrm{RCH}$ and delivery services. Briefly, the study enrolled women in their third trimester of pregnancy and followed them at birth, at 7 days post delivery, and monthly up to 6 months after delivery, and thereafter every 3rd month up to 1 year post delivery [27, 28]. 
The larger study aimed to describe knowledge of optimal breastfeeding practices and intention to exclusive breastfeed during pregnancy and how they influence optimal breastfeeding practices of the infants after delivery [27]. The parent study also aimed to measure the rate of exclusive breastfeeding by using different methods of measurement [29]. This paper used the data that was collected from enrolment, delivery and up to 7 days after delivery.

\section{Study population and data collection procedures Population}

The study population for this paper was all women who were enrolled during pregnancy, were followed at birth and at 7 days post-delivery and had complete information on time of breastfeeding initiation. The parent study enrolled 536 pregnant women in their third trimester and 413 women had complete information on time of initiation of breastfeeding, thus involved in the analysis (Fig. 1).

\section{Sample size}

Sample size for this analysis was estimated by using the formula for precision

$$
N=Z 2 * P(1-P) / \varepsilon 2
$$

Where $N$ is estimated minimum sample size; $Z$ is confidence level at $95 \%$ (standard value is 1.96); $P$ is proportion (prevalence of early initiation of breastfeeding in Kilimanjaro region of $73.7 \%$ by [22]; $\varepsilon$ is precision at 95\% CI $=0.05$.

The minimum sample that was required for this study was 298 women. Addition of $10 \%$ for non-response gave a minimum sample of 328 pregnant women.

\section{Study procedures}

Before enrollment, pregnant women were informed about the study aims and follow up procedures. The women who gave an informed consent and who reported they would be in Moshi for at least 9 months

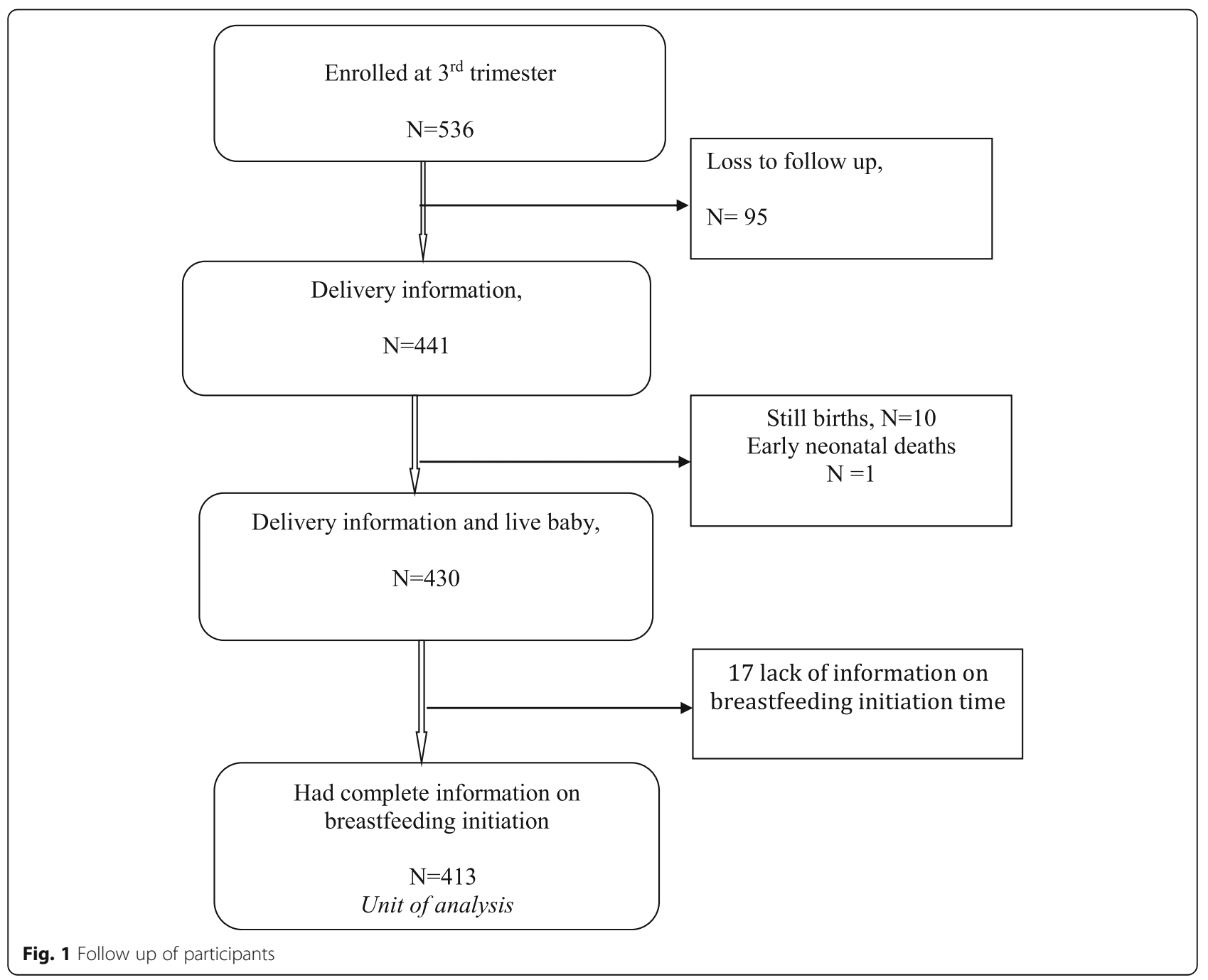


after delivery were enrolled in the study. After consenting, face- to-face interviews were conducted using a questionnaire by trained nurses/ junior doctors. The interviews were in Swahili.

At enrollment the questionnaire was used and it collected information on: socio-demographic and economic characteristics, partners' characteristics, reproductive health information including parity, timing and frequency of antenatal attendance, information on counseling on breastfeeding or infant feeding during antenatal visits, and type of advice on breastfeeding given. Information on breastfeeding knowledge was also collected and it included knowledge on colostrum, pre-lacteal feeding, knowledge on optimal time to initiate breastfeeding and knowledge on exclusive breastfeeding definition and duration.

At delivery a standardized tool was used to collect information on; place of delivery, mode of delivery, sex, weight and length of the baby, if the baby was term or preterm and feeding/ breastfeeding information. The tool at 7 days visit included information on exclusive breastfeeding; any breastfeeding problems (mastitis, engorgement, cracked nipple) and ascertained information on time of breastfeeding initiation.

\section{Data analysis}

Data was extracted and analysed by using SPSS version 23. Cleaning was conducted using frequencies and all the entries with missing values for the key outcome variable i.e. early initiation of breast feeding were removed. Descriptive statistics were used to summarize characteristics of study participants: continuous variables were summarized by using mean and standard deviation (SD) and categorical variables were summaries by using frequency and proportions. Odds ratio and 95\% confidence interval were used to measure the strength of association between early initiation of breastfeeding and independent variables. Multivariable log-binomial regression was used to determine the factors independently associated with early initiation of breastfeeding. The $p$ value of less than 0.05 was considered as statistical significant.

\section{Categorization of variables}

Early initiation of breast feeding is defined by WHO as initiation of breastfeeding within $1 \mathrm{~h}$ of birth [1]. Categorization of breastfeeding initiation was as follows: within $1 \mathrm{~h}$ after birth; $2-23 \mathrm{~h}$; and 24 or more hours after birth. Age of participants which was collected as numerical variable and was categorized $(<20,20-34$, and $35-$ 49). Marital status was categorized as those in union vs. not in union, and parity as (first and second or more).

Categorization of knowledge of early initiation of breastfeeding practices was measured through a series of questions and those participate who mentioned a child should be put on breast within an hour after birth were categorized as having knowledge on early initiation of breastfeeding. Knowledge on colostrum and its advantages was assessed and women who reported that it is important that the newborn should be given colostrum were categorized as having knowledge.

\section{Results \\ Background characteristics of the participants Socio demographic characteristics of the women}

The mean age of the 413 participants was 26.3 (SD 5.6) years. Most of the women were married/cohabiting 371 (89.8\%), and were not employed in formal sector 371 (89.8\%). Nearly one third of the women 144 (34.9\%) had an income per month of less or equal to 60,000 Tanzanian shillings ( $\leq 30$ USD). Other socio demographic characteristics are shown in (Table 1).

\section{Reproductive characteristics, knowledge of breastfeeding and practices}

The majority of the 413 women (99\%) delivered at the health facility and mode of delivery was vaginal delivery (88\%), Table 2 . The majority of the women $(94.7 \%)$ had good knowledge on colostrum giving and its importance and $71 \%$ of the women had knowledge that breastfeeding should be started within $1 \mathrm{~h}$ after birth. About $94 \%$ of the 413 women gave colostrum and $7 \%$ reported to have given pre-lacteal feeds. Missed opportunity for counseling was reported, as only $54 \%$ of the women reported to have received counseling on breastfeeding issues during pregnancy.

\section{Prevalence of early initiation of breastfeeding}

Of the 413, the prevalence of early initiation of breastfeeding was $83.1 \%$, (Table 2). Nearly $5 \%$ of the newborns were breastfed after $24 \mathrm{~h}$ of birth.

\section{Factors associated with early initiation of breastfeeding}

Table 3 depicts the association of socio-demographic characteristics with early initiation of breastfeeding.

In unadjusted model clinic of enrolment was significantly associated with EIBF, but the results were not significant in adjusted model. Other factors like age of the mother, marital status, mother's education level, mother's occupation, mother's income level, and partner education level and partner occupation status were assessed but they were not significantly associated with early initiation of breastfeeding.

The association between early initiation of breastfeeding with knowledge, breastfeeding practices and reproductive health factors is shown in Table 4. In multivariable regression analysis, Women who had caesarean section had 93\% less odds of initiating breastfeeding early compared to women who gave birth by vaginal 
Table 1 Socio-demographic characteristics of women in Moshi municipal by clinics $(N=413)$

\begin{tabular}{|c|c|c|c|}
\hline \multirow[t]{2}{*}{ Characteristics } & \multirow{2}{*}{$\begin{array}{l}\text { Overall } \\
\text { Frequency } \\
(\%)\end{array}$} & \multicolumn{2}{|l|}{ Health Facility } \\
\hline & & $\begin{array}{l}\text { Pasua }(\boldsymbol{n}=228) \\
\text { Frequency }(\%)\end{array}$ & $\begin{array}{l}\text { Majengo }(\boldsymbol{n}=185) \\
\text { Frequency }(\%)\end{array}$ \\
\hline \multicolumn{4}{|l|}{ Maternal age (years) } \\
\hline$<20$ & $39(9.4)$ & $27(11.8)$ & $12(6.5)$ \\
\hline $20-34$ & $338(81.9)$ & $187(82.0)$ & $151(81.6)$ \\
\hline$\geq 35$ & $36(8.7)$ & $14(6.2)$ & $22(11.9)$ \\
\hline \multicolumn{4}{|l|}{ Religion } \\
\hline Christian & $234(56.7)$ & $92(40.4)$ & $142(76.8)$ \\
\hline Muslim & $179(43.3)$ & $136(59.6)$ & $43(23.2)$ \\
\hline \multicolumn{4}{|l|}{ Marital status } \\
\hline Single/widow/Separated & $42(10.1)$ & $23(10.1)$ & $19(10.3)$ \\
\hline Married/Cohabiting & $371(89.8)$ & $205(89.9)$ & $166(89.7)$ \\
\hline \multicolumn{4}{|l|}{ Education status } \\
\hline None and primary & $254(61.5)$ & $153(67.1)$ & $101(54.6)$ \\
\hline Secondary and above & $159(38.5)$ & $75(32.9)$ & $84(45.4)$ \\
\hline \multicolumn{4}{|l|}{ Occupation status $(N=410)$} \\
\hline Self employed & $371(90.5)$ & $211(93.3)$ & $160(87.0)$ \\
\hline Employed & $39(9.5)$ & $15(6.6)$ & $24(13.0)$ \\
\hline \multicolumn{4}{|l|}{ Maternal income* $(N=284)$} \\
\hline$\leq 60,000$ Tshs & $144(50.7)$ & $92(53.2)$ & $52(46.8)$ \\
\hline$>60,000$ Tshs & $140(49.3)$ & $81(46.8)$ & $59(53.2)$ \\
\hline \multicolumn{4}{|l|}{ Alcohol use } \\
\hline Yes & $61(14.8)$ & $16(7.0)$ & $45(24.3)$ \\
\hline No & $352(85.2)$ & $212(93.0)$ & $140(75.7)$ \\
\hline \multicolumn{4}{|l|}{ Partners information's } \\
\hline \multicolumn{4}{|l|}{ Education level $(N=408)$} \\
\hline None and primary & $221(54.2)$ & $130(57.8)$ & $91(49.7)$ \\
\hline Secondary and above & $187(45.8)$ & $95(42.2)$ & $92(50.3)$ \\
\hline \multicolumn{4}{|c|}{ Occupation status ( $N=412)$} \\
\hline Self employed & $246(59.7)$ & $143(63.0)$ & $103(55.7)$ \\
\hline Employed & $166(40.3)$ & $84(37.0)$ & $82(44.3)$ \\
\hline \multicolumn{4}{|l|}{ Child information } \\
\hline \multicolumn{4}{|l|}{ Sex of the child $(N=409)$} \\
\hline Male & $201(49.1)$ & $107(47.8)$ & $94(50.8)$ \\
\hline Female & $208(50.9)$ & $117(52.2)$ & $91(49.2)$ \\
\hline
\end{tabular}

*At the time of the study 1 USD $=2000 \mathrm{TZS}$

delivery (Adjusted odds ratio $(\mathrm{AOR})=0.07(0.03-0.16)$. Women who had knowledge on time of breastfeeding initiation during pregnancy had 3 times more higher odds to initiate breastfeeding early compared to others (Adjusted OR = 3.01 (1.56-5.81).

\section{Discussion}

In this study, $83 \%$ of the women breastfed their newborns within the $1 \mathrm{~h}$ after birth. Mode of delivery and mode of delivery were the independent factors associated with of early initiation of breastfeeding.

The prevalence of early initiation of breastfeeding observed in the current study of $83 \%$ is higher than the proportions reported in earlier studies in Kilimanjaro region. Over time proportion of women initiating breastfeeding within an hour of birth increased from $70 \%$ in 2002-06 [30] to 77\% in 2010-11 [31]. Tanzania Demographic and Health Survey of 2015-16 reported the 
Table 2 Reproductive health characteristics, knowledge on breastfeeding and practices among 413 women in Moshi municipal

\begin{tabular}{|c|c|c|c|}
\hline \multirow{2}{*}{$\begin{array}{l}\text { Knowledge and reproductive } \\
\text { health characteristics }\end{array}$} & \multirow{2}{*}{$\begin{array}{l}\text { Overall } \\
\text { Frequency } \\
(\%)\end{array}$} & \multicolumn{2}{|l|}{ Health Facility } \\
\hline & & $\begin{array}{l}\text { Pasua }(\boldsymbol{n}=228) \\
\text { Frequency (\%) }\end{array}$ & $\begin{array}{l}\text { Majengo }(\boldsymbol{n}=185) \\
\text { Frequency }(\%)\end{array}$ \\
\hline \multicolumn{4}{|l|}{ Number of ANC visit $(N=407)$} \\
\hline$<4$ visits & $274(67.3)$ & $173(75.9)$ & $101(56.4)$ \\
\hline$\geq 4$ visits & $133(32.7)$ & $55(24.1)$ & $78(43.6)$ \\
\hline \multicolumn{4}{|l|}{ Parity $(N=268)$} \\
\hline Prime & $138(51.5)$ & $76(47.5)$ & $62(57.4)$ \\
\hline Multipara & $130(48.5)$ & $84(52.5)$ & $46(42.6)$ \\
\hline \multicolumn{4}{|c|}{ Counseled on BF/infant feeding at ANC visit } \\
\hline No & $189(45.8)$ & $95(41.7)$ & $94(50.8)$ \\
\hline Yes & $224(54.2)$ & $133(58.3)$ & $91(49.2)$ \\
\hline \multicolumn{4}{|l|}{ Type of advice given ${ }^{a}$} \\
\hline Correct positioning (Yes) & $117(28.3)$ & $56(24.6)$ & $61(33.0)$ \\
\hline Correct attachment (Yes) & $92(22.3)$ & $44(19.3)$ & $48(25.9)$ \\
\hline Solving BF problem (Yes) & $41(9.9)$ & $38(16.7)$ & $3(1.6)$ \\
\hline Colostrum giving (Yes) & $88(21.3)$ & $53(23.2)$ & $35(18.9)$ \\
\hline Exclusive breastfeeding only (Yes) & $185(44.8)$ & $107(46.9)$ & $78(42.2)$ \\
\hline \multicolumn{4}{|c|}{ Knowledge on time of breastfeeding initiation } \\
\hline After $1 \mathrm{~h}$ of delivery (delay) & $27(6.5)$ & $13(5.7)$ & $14(7.6)$ \\
\hline Within $1 \mathrm{~h}$ after delivery (early) & $293(71.0)$ & $166(72.8)$ & $127(68.6)$ \\
\hline Don't know & $93(22.5)$ & $49(21.5)$ & $44(23.8)$ \\
\hline \multicolumn{4}{|l|}{ Knowledge on colostrum giving } \\
\hline No & $12(2.9)$ & $9(3.9)$ & $3(1.6)$ \\
\hline Yes & $391(94.7)$ & $216(94.7)$ & $175(94.6)$ \\
\hline Don't know & $10(2.4)$ & $3(1.4)$ & $7(3.8)$ \\
\hline \multicolumn{4}{|l|}{ Information collected after delivery } \\
\hline \multicolumn{4}{|l|}{ Place of delivery $(N=410)$} \\
\hline Home & $3(0.8)$ & $2(0.9)$ & $1(0.5)$ \\
\hline Health institution & 407 (99.2) & $223(99.1)$ & $184(99.5)$ \\
\hline \multicolumn{4}{|l|}{ Mode of delivery $(N=408)$} \\
\hline Caesarean Section & $46(11.3)$ & $21(9.3)$ & $25(13.7)$ \\
\hline Vaginal delivery & $362(88.7)$ & $205(90.7)$ & $157(86.3)$ \\
\hline \multicolumn{4}{|c|}{ Colostrum giving practice $(N=412$ ) } \\
\hline No & $25(6.1)$ & $18(7.9)$ & $7(3.8)$ \\
\hline Yes & $387(93.9)$ & $209(92.1)$ & $178(96.2)$ \\
\hline \multicolumn{4}{|l|}{ Time of BF initiation } \\
\hline Within $1 \mathrm{~h}$ after birth & $343(83.1)$ & $205(89.9)$ & $138(74.6)$ \\
\hline $2-23 \mathrm{~h}$ after birth & $51(12.3)$ & $22(9.7)$ & $29(15.7)$ \\
\hline$\geq 24 \mathrm{~h}$ after birth & $19(4.6)$ & $1(0.4)$ & $18(9.7)$ \\
\hline \multicolumn{4}{|l|}{ Pre-lacteal feeds practice } \\
\hline Provided & $28(6.8)$ & $5(2.2)$ & $23(12.4)$ \\
\hline Not provided & $385(93.2)$ & $223(97.8)$ & $162(87.6)$ \\
\hline
\end{tabular}

a: Multiple answered were recorded with Yes or No answer. 
Table 3 Association between socio-demographic factors and early initiation of breastfeeding among women in Moshi municipal, $(N=413)$

\begin{tabular}{|c|c|c|c|c|}
\hline Variables & $\begin{array}{l}\text { Total } \\
\text { (N) }\end{array}$ & $\begin{array}{l}\text { ElBF } \\
n(\%)\end{array}$ & $\begin{array}{l}\text { Crude OR } \\
{[95 \% \mathrm{Cl}]}\end{array}$ & Adjusted OR $[95 \% \mathrm{Cl}]$ \\
\hline \multicolumn{5}{|l|}{ Maternal age (years) } \\
\hline$<20$ & 39 & $36(92.3)$ & $1.11[1.01-1.23]$ & $0.99[0.63-1.54]$ \\
\hline $20-34$ & 338 & $280(82.8)$ & 1.0 & 1.0 \\
\hline$\geq 35$ & 36 & $27(75.0)$ & $0.91[0.75-1.10]$ & $0.75[0.24-2.39]$ \\
\hline \multicolumn{5}{|l|}{ Marital status } \\
\hline Unmarried & 42 & $33(78.6)$ & $0.90[0.4-2.0]$ & $0.93[0.41-2.14]$ \\
\hline Married/cohabiting & 371 & $310(83.6)$ & 1.0 & 1.0 \\
\hline \multicolumn{5}{|l|}{ Education status } \\
\hline None and primary & 254 & $209(82.3)$ & 1.0 & 1.0 \\
\hline Secondary and above & 159 & $134(84.3)$ & $1.02[0.94-1.12]$ & $0.95[0.42-1.24]$ \\
\hline \multicolumn{5}{|l|}{ Maternal income } \\
\hline$\leq 60,000$ Tshs & 144 & $119(82.6)$ & 1.0 & 1.0 \\
\hline$>60,000$ Tshs & 140 & $119(85.0)$ & $1.19[0.63-2.24]$ & $1.31[0.61-2.82]$ \\
\hline \multicolumn{5}{|l|}{ Partner education level } \\
\hline None and primary & 221 & $180(81.5)$ & 1.0 & 1.0 \\
\hline Secondary and above & 187 & $159(85.0)$ & $1.29[0.76-2.19]$ & $1.82[0.84-3.96]$ \\
\hline \multicolumn{5}{|c|}{ Partner occupation status } \\
\hline Self employed & 246 & $204(82.9)$ & 1.0 & 1.0 \\
\hline Employed & 166 & $138(83.1)$ & $1.01[0.60-1.71]$ & $0.73[0.36-1.49]$ \\
\hline \multicolumn{5}{|l|}{ Health facility enrolled } \\
\hline Pasua & 228 & $205(89.9)$ & 1.0 & 1.0 \\
\hline Majengo & 185 & $138(74.6)$ & $0.73[0.68-0.80]$ & $0.93[0.76-1.15]$ \\
\hline
\end{tabular}

Adjusted for maternal age, marital status, mother's education level, mother's income level, partner education level, partner occupation status and health facility women enrolled

national prevalence of early initiation of breastfeeding of $51 \%$, with wide regional variations; ranging from $26 \%$ in Simiyu region to $80 \%$ in Tanga region. Kilimanjaro region had prevalence of $74 \%$ according to the TDHS of $2015 / 16$. It seems over time women in the region are adapting positive practices of early initiation of breastfeeding. In this study, high early initiating of breastfeeding was paralleled with overall high knowledge on colostrum and its importance (94.7\%), knowledge on definition and time for exclusive breastfeeding $(81 \%)$ and knowledge that newborns should start to be breastfeeding within $1 \mathrm{~h}$ (71.0\%) [27]. Community and facility awareness and education campaigns are still needed, as WHO and UNICEF recommend that every newborn should be put on breast within the first hour after birth as "it gives them the best chance to survive" $[1,4]$.

Women who had correct knowledge on time of breastfeeding initiation during pregnancy, had higher odds of initiating breastfeeding within $1 \mathrm{~h}$ after birth. Studies in Ethiopia, revealed that those women who receive proper counseling on breastfeeding during pregnant are more likely to have early breastfeeding initiation $[19,32]$.
Similar findings were also observed in Brazil [15], showing the need to improve counseling on optimal breastfeeding practices among women during antennal period.

There was however, missed opportunity to improve early initiation of breastfeeding and overall optimal breastfeeding practices in this setting. Despite the fact there is universal antenatal care attendance at least once and high health facility delivery (90\%) in TDHS and 99\% in this study, only $54 \%$ of the women reported to have received counseling on breastfeeding or on infant feeding during pregnancy [27]. In Tanzania, more women are attending for pregnancy care and are delivering at the health facilities with skilled providers. Proportion of births attended by skilled providers has increased from $46 \%$ in $2004-05,51 \%$ in 2010 and $64 \%$ in $2015-16$ as reported by Demographic and Health survey. This is in contrast to early initiation of breastfeeding where rates have declined from 59\% in 2004-05, to $49 \%$ in 2010 and slightly rose to $51 \%$ in $2015-16$ survey [14]. Health providers need to use the opportunity to have intensive and sustained education and communication campaigns on optimal breastfeeding practices including early initiation 
Table 4 Multivariable log-binomial regression to determine association between reproductive health factors, knowledge of breastfeeding and practices with early initiation of breastfeeding in Moshi municipal $(N=413)$

\begin{tabular}{|c|c|c|c|c|}
\hline Variables & $\begin{array}{l}\text { Total } \\
(\mathrm{N})\end{array}$ & $\begin{array}{l}\text { ElBF } \\
\text { n (\%) }\end{array}$ & $\begin{array}{l}\text { Crude OR } \\
{[95 \% \mathrm{Cl}]}\end{array}$ & Adjusted OR [95\% Cl] \\
\hline \multicolumn{5}{|l|}{ Number of ANC visit } \\
\hline$<4$ visits & 274 & $235(85.8)$ & 1.0 & 1.0 \\
\hline$\geq 4$ visits & 133 & $105(79.0)$ & $0.79[0.72-1.06]$ & $0.96[0.83-1.10]$ \\
\hline \multicolumn{5}{|l|}{ Parity } \\
\hline Prime & 138 & $113(81.9)$ & 1.0 & 1.0 \\
\hline Multipara & 130 & $108(83.1)$ & $1.01[0.91-1.13]$ & $1.02[0.91-1.14]$ \\
\hline \multicolumn{5}{|c|}{ Type of advice given during ANC ${ }^{a}$} \\
\hline Correct positioning (Yes) & 117 & $97(82.9)$ & $1.01[0.89-1.14]$ & $0.92[0.80-1.07]$ \\
\hline Correct attachment (Yes) & 92 & $76(82.6)$ & $1.00[0.88-1.13]$ & $0.97[0.86-1.11]$ \\
\hline Colostrum giving (Yes) & 88 & $74(84.1)$ & $1.03[0.91-1.17]$ & $1.01[0.86-1.13]$ \\
\hline EBF only (Yes) & 185 & $153(82.7)$ & $1.02[0.85-1.22]$ & $0.39[0.19-0.80]$ \\
\hline \multicolumn{5}{|c|}{ Knowledge on timely BF initiation during pregnancy } \\
\hline Others ${ }^{b}$ & 66 & $46(69.7)$ & 1.0 & 1.0 \\
\hline Within $1 \mathrm{~h}$ (timely) & 347 & $297(85.6)$ & $2.59[1.41-4.74]$ & $3.01[1.56-5.81]$ \\
\hline \multicolumn{5}{|c|}{ Information collected after delivery } \\
\hline \multicolumn{5}{|l|}{ Mode of delivery } \\
\hline Caesarean section & 46 & $17(37.0)$ & $0.08[0.04-0.07]$ & $0.07[0.03-0.16]$ \\
\hline Vaginal delivery & 362 & $321(88.7)$ & 1.0 & 1.0 \\
\hline
\end{tabular}

a: Yes vs No

b:others (mentioned initiation after $1 \mathrm{~h}$, I don't know)

Adjusted for number of antenatal care (ANC) visits, parity, type of advice given during ANC, knowledge of early initiation of BF, and mode of delivery.

of breastfeeding when meeting women during pregnancy, delivery and postnatal care.

Providers should be educated to understand the critical role they have in reducing mortality among neonates. By using the critical moment to start breastfeeding, they are contributing in reducing neonatal mortality, infection related mortality and child mortality. Further, neonatal mortality accounts for $40-47 \%$ of child mortality [1, 5], therefore improving optimal breastfeeding practices especially early initiation of breastfeeding may be one of key interventions in countries with high neonatal mortality like Tanzania (21 per 1000 live births) and help to accelerate the achievement of SDG 3.2 of reducing preventable newborn and child deaths deaths to 12 and 25 per 1000 live births by 2030 [13, 33].

Mode of delivery was a strong predictor of early initiation of breastfeeding in this study. Women with vaginal delivery were three times more likely to practice early initiation of breastfeeding compared to caesarean section. Similar observations have been noted in studies conducted in Ethiopia, Nigeria, India, Brazil as well as in Tanzania which reported that women who had ceasarian section had delay initiation of breastfeeding compared to those with vaginal delivery $[17,18,20,21,34]$. Women who have undergone ceasarian section may have experienced maternal pain, fear and stress, fatique and prolonged recovery [35]. Furthermore, infant born by Ceasarian section are more likely to have respiratory distress that might cause a newborn to be taken to intensive care unit consequently being separated from mother [16] while the reasons above might offer an explanation, each individual facility should have policies and interventions in place that would try to initiate breastfeeding in optimal manner even among women who have undergone caesarean section.

There was lack of association between early initiation of breastfeeding and sex of the baby, residency, and wealth of the household or parental education level. This is similar to demographic and health survey results of 2015-16 in Tanzania and by WHO \& UNICEF of 2018. It is in contrast to other studies in India where older women ( $\geq 35$ years) were less likely to initiate breastfeeding early than younger women [36] and in Ethiopia where mothers from wealthier households were more likely to commence breastfeeding early as compared to mothers from poorest household [17]. However in all studies similar to this, very few individual factors influenced early initiation of breastfeeding. It points to the fact that health facility factors would be more important and studies are needed to understand the gaps and dynamics of how facilities handle essential newborn care [37]. Globally, $70 \%$ of the women deliver at health 
facilities, and facilities are with women in the first hour after delivery hence more roles to play in improving initiation of breastfeeding at optimal moments/ time.

\section{Strength and limitations}

Early initiation of breastfeeding information's was collected based on women self-report; this may lead to over reporting of the behavior. However the interviews were conducted within $24 \mathrm{~h}$ of delivery and thus minimized recall bias. Health facility factors like training of providers in breastfeeding or years of experience that may have influenced counselling and support for EIBF at facilty level were not collected in this study.

However, the study has strength of being prospectively in nature that allowed mothers to be enrolled in the study before delivery and to be visited shortly after delivery which helps to overcome recall bias. While the study was health facility based, proportion of women who delivered at health facilities was nearly universal (99\%), therefore the results can be generalized to women of reproductive age in the municipal.

\section{Conclusion}

Prevalence of early initiation of breastfeeding in Moshi Municipal was high (83.1\%) but was below WHO recomandation of $90 \%$. Knowledge on correct time of breastfeeding initiation during pregnancy and mode of delivery were the independent predictors of early initiation of breastfeeding.

In order to improve the rate of early initition of breastfeeding in Moshi Municipal, District Health Management team should strengthening interventions on promotion and supporting early initiation of breastfeeding. Counselling on optimal BF and EIBF should be strengthened and promoted. Given high facility deliveries, immediate support after delivery on attachment and positioning might help to improve early initiation of breastfeeding. Moreover, more reseach especially qualitative should be done in Majengo health center to explore more on why most women delayed to initiate breastfeeding as recommended by WHO.

\section{Abbreviations}

ANC: Antenatal care; BF: Breastfeeding; BFHI: Baby Friendly Hospital Iniative; EBF: Exclusive Breastfeeding; ElBF: Early Initiation of Breastfeeding; RCH: Reproductive and Child Health; SDGs: Sustainable Development Goals; WHO: World Health Organization

\section{Acknowledgements}

We thank the women who accepted to participate in the study and Beatrice Kisanga, Adventina Mlaki, Semphorosa Mshanga and Anna Mlingi for assistance in data collection. We also thank the Regional and District Medical Officers for permission to conduct the study.

\section{Authors' contributions}

$\mathrm{THH}, \mathrm{MM}, \mathrm{BS}-\mathrm{P}, \mathrm{MW}$ and SEM contributed to the design of the study. HYL, $\mathrm{THH}, \mathrm{MM}$ and SEM collected the data. $\mathrm{HYL}, \mathrm{THH}$ and MM analyzed the data. $H Y L, T H H, M M$, and SEM interpreted the results. HYL and THH prepared the manuscript and all the other authors reviewed the manuscript critical inputs before submission. All authors read and approved the final manuscript.

\section{Funding}

The funding for conducting this study was secured from The Letten Foundation of Norway. Sia E. Msuya was THRiVE-2 faculty and partially supported by the DELTAS Africa Initiative grant \# DEL-15-011 to THRiVE-2.

The funders did not have any role or influence the design of the study, data collection, analysis or interpretation of the results and in the development of the manuscript

\section{Availability of data and materials \\ The dataset analysed for the current study is available from the corresponding author on reasonable request.}

Ethics approval and consent to participate

The Ethical clearance was sought from College Research and Ethical Review Committee (CRERC) of Kilimanjaro Christian Medical University College with certificate number 2047 and Regional Committee for Medical and Health Research Ethics, Norway (2016/109/REK sør-øst). Permission to conduct the study at Municipal facilities was sought from Moshi Municipal District Medical Officer and heads of Majengo and Pasua health committees. Before the enrollment a written informed consent was sought from each participant and thumb print was used for those who did not know how to write. Code numbers were used at data collection tools to ensure anonymity.

Consent for publication

Not applicable.

\section{Competing interests}

The authors declare that they have no competing interests.

\section{Author details}

${ }^{1}$ Institute of Public Health, Department of Community Health, Kilimanjaro Christian Medical University College (KCMUCo), Moshi, Tanzania. ${ }^{2}$ Better Health for African Mother and Child (BHAMC), P.O. Box 8418, Moshi, Tanzania. ${ }^{3}$ Institute of Basic Medical Sciences, Department of Nutrition, University of Oslo, Oslo, Norway. ${ }^{4}$ Division of Gynaecology and Obstetrics, Oslo University Hospital, Rikshospitalet, Oslo, Norway. ${ }^{5}$ Institute of Clinical Medicine, University of Oslo, Oslo, Norway. ${ }^{6}$ Institute of Public Health, Department of Epidemiology \& Biostatistics, Kilimanjaro Christian Medical University College (KCMUCo), Moshi, Tanzania. ${ }^{7}$ Department of Community Medicine, Kilimanjaro Christian Medical Centre (KCMC), Moshi, Tanzania.

Received: 17 April 2019 Accepted: 22 April 2020

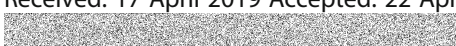

References

1. WHO and, UNICEF. Capture the Moment - Early initiation of breastfeeding: The best start for every newborn. New York. 2018.

2. Edmond KM, Zandoh C, Quigley MA, Amenga-Etego S, Owusu-Agyei S, Kirkwood BR. Delayed breastfeeding initiation increases risk of neonatal mortality. Pediatrics. 2006;117(3):e380-e6.

3. Edmond KM, Kirkwood BR, Amenga-Etego S, Owusu-Agyei S, Hurt LS. Effect of early infant feeding practices on infection-specific neonatal mortality: an investigation of the causal links with observational data from rural Ghana. Am J Clin Nutr. 2007:86(4):1126-31.

4. WHO. Every newborn: an action plan to end preventable deaths 2014 [Available from: http://www.who.int/pmnch/ewec_progressreport.pdf?ua=1.

5. UNICEF. From the first hour of life: making the case for improved infant and young child feeding everywhere 2016 [Available from: https://www.unicef. org/publications/index_93027.html.

6. NEOVITA Study Group. Timing of initiation, patterns of breastfeeding, and infant survival: prospective analysis of pooled data from three randomised trials. Lancet Glob Health. 2016:4(4):e266-e75.

7. Smith ER, Hurt L, Chowdhury R, Sinha B, Fawzi W, Edmond KM, et al. Delayed breastfeeding initiation and infant survival: a systematic review and meta-analysis. PLoS One. 2017;12(7):e0180722. 
8. Smith ER, Locks LM, Manji KP, McDonald CM, Kupka R, Kisenge R, et al. Delayed breastfeeding initiation is associated with infant morbidity. J Pediatr. 2017;191:57-62.

9. Debes AK, Kohli A, Walker N, Edmond K, Mullany LC. Time to initiation of breastfeeding and neonatal mortality and morbidity: a systematic review. BMC Public Health. 2013;13(S3):S19.

10. Khan J, Vesel L, Bahl R, Martines JC. Timing of breastfeeding initiation and exclusivity of breastfeeding during the first month of life: effects on neonatal mortality and morbidity - a systematic review and meta-analysis. Matern Child Health J. 2015;19(3):468-79.

11. Sobhy S, Mohame N. The effect of early initiation of breast feeding on the amount of vaginal blood loss during the fourth stage of labor. J Egyptian Public Health Assoc. 2004;79(1-2):1-12.

12. WHO. Recommendatios for the prevention and treatment of postpartum haemorrhage. 2012 [Available from: www.who.int/reproductivehealth/ publications/maternal_perinatal_health/9789241548502/en. .

13. UNICEF. Infant and young chilld feeding. 2018 .

14. Ministry of Health Community Development Gender Elderly, and Children, (MoHCDGEC), [Tanzania Mainland], Ministry of Health (MoH) [Zanzibar] National Bureau of Statistics (NBS); Office of the Chief Government Statistician (OCGS) and ICF International,. Tanzania Demographic Health Survey and Malaria Indicator Survey (TDHS-MIS). 2015-16.

15. Vieira TO, Vieira GO, Giugliani ERJ, Mendes CM, Martins CC, Silva LR Determinants of breastfeeding initiation within the first hour of life in a Brazilian population: cross-sectional study. BMC Public Health. 2010;10(1): 760.

16. Liben ML, Yesuf EM. Determinants of early initiation of breastfeeding in Amibara district, northeastern Ethiopia: a community based cross-sectional study. Int Breastfeed J. 2016;11(1):7.

17. Berde AS, Yalcin SS. Determinants of early initiation of breastfeeding in Nigeria: a population-based study using the 2013 demograhic and health survey data. BMC Pregnancy Childbirth. 2016;16(1):32

18. Exavery A, Kanté AM, Hingora A, Phillips JF. Determinants of early initiation of breastfeeding in rural Tanzania. Int Breastfeed J. 2015;10(1):27.

19. Setegn T, Gerbaba M, Belachew T. Determinants of timely initiation of breastfeeding among mothers in Goba Woreda, south East Ethiopia: a cross sectional study. BMC Public Health. 2011;11(1):217.

20. Sarkar TK, Bhattacherjee S, Mukherjee A, Saha TK, Chakraborty M, Dasgupta S. Early initiation of breast feeding in tribal children. Int J Commun Med Public Health. 2016;3(11):3081-5.

21. Aguayo VM, Gupta G, Singh G, Kumar R. Early initiation of breast feeding on the rise in India. BMJ Glob Health. 2016;1(2):e000043.

22. Mlay B. Knowledge, attitude and supportive practices on exclusive breastfeeding among health care providers' in Hai and Siha districts, Kilimanjaro region, Tanzania; 2011.

23. National Bureau of Statistics (NBS) Tanzania, and ORC Macro. Tanzania Demographic and Health Survey 2004-2005. 2005.

24. National Bureau of Statistics (NBS) Tanzania, and ICF Macro. Tanzania Demographic and Health Survey 2010. 2011.

25. UN. About the Sustainable Development Goals 2015 [Available from: https://www.un.org/sustainabledevelopment/health/.

26. National Bureau of Statistics (NBS) Ministry of Finance Dar-es-salaam, Office of Chief Government Statistician President's Office Finance Economy and Development Planning Zanzibar. Population Distribution by Age and Sex. 2013.

27. Hashim TH, Mgongo M, Katanga J, Uriyo JG, Damian DJ, Stray-Pedersen B, et al. Predictors of appropriate breastfeeding knowledge among pregnant women in Moshi urban, Tanzania: a cross-sectional study. Int Breastfeed J. 2016;12(1):11.

28. Stephen G, Mgongo M, Hussein Hashim T, Katanga J, Stray-Pedersen B, Msuya SE. Anaemia in pregnancy: prevalence, risk factors, and adverse perinatal outcomes in northern Tanzania. Anemia. 2018;2018.

29. Hussein TH, Mgongo M, Uriyo JG, Damian DJ, Stray-Pedersen B, Msuya SE, et al. Exclusive breastfeeding rates and factors associated with exclusive breastfeeding practices in northern Tanzania: measurement using two different methodologies -24 hours recall and recall since birth. Int J MCH AIDS. 2019;8(1):32.

30. Hussein TH, Mgongo M, Uriyo JG, Damian DJ, Stray-Pedersen B, Msuya SE. Exclusive breastfeeding up to six months is very rare in Tanzania: a cohort study of infant feeding practices in Kilimanjaro area. Science. 2015;3(2):251-8
31. Mgongo M, Hashim TH, Uriyo JG, Damian DJ, Stray-Pedersen B, Msuya SE, et al. Determinants of exclusive breastfeeding in Kilimanjaro region, Tanzania. Science J Public Health. 2014;2(6):631-5.

32. Tewabe T. Timely initiation of breastfeeding and associated factors among mothers in Motta town, east Gojjam zone, Amhara regional state, Ethiopia, 2015: a cross-sectional study. BMC pregnancy and childbirth. 2016;16(1):314.

33. WHO. Sustainable Development Goals. 17 Goals to transform our world. . 2015.

34. Kounnavong S, Pak-Gorstein S, Akkhavong K, Palaniappan U, Berdaga V, Conkle J, et al. Key determinants of optimal breastfeeding practices in Laos. Food Nutr Sci. 2013:4(10):61.

35. Dickens $\vee$. Counseling the nursing mother: a lactation consultant's guide; 2011

36. Patel A, Badhoniya N, Khadse S, Senarath U, Agho KE, Dibley MJ, et al. Infant and young child feeding indicators and determinants of poor feeding practices in India: secondary data analysis of National Family Health Survey 2005-06. Food Nutr Bull. 2010;31(2):314-33.

37. Mrisho M, Schellenberg JA, Mushi AK, Obrist B, Mshinda H, Tanner M, et al. Understanding home-based neonatal care practice in rural southern Tanzania. Trans R Soc Trop Med Hyg. 2008;102(7):669-78.

\section{Publisher's Note}

Springer Nature remains neutral with regard to jurisdictional claims in published maps and institutional affiliations.
Ready to submit your research? Choose BMC and benefit from:

- fast, convenient online submission

- thorough peer review by experienced researchers in your field

- rapid publication on acceptance

- support for research data, including large and complex data types

- gold Open Access which fosters wider collaboration and increased citations

- maximum visibility for your research: over $100 \mathrm{M}$ website views per year

At BMC, research is always in progress.

Learn more biomedcentral.com/submissions 